\title{
Auction Versus Negotiated SALE: \\ EVIDENCE FROM REAL ESTATE SALES
}

\author{
YuenLeng $\mathrm{CHOW}^{*}$ \\ National University of Singapore
}

Isa HAFALIR

Carnegie Mellon University

Abdullah YAVAS

University of Wisconsin-Madison

This draft: February 08, 2011

The authors wish to thank Seow Eng Ong for the use of the data. We would also like to thank Austin Jaffe, Kenneth Lusht, Brent Ambrose, Edward Coulson, Kerry Vandell, and participants at the 2008 American Real Estate and Urban Economics Association Conference for their useful comments. 


\title{
Auction Versus Negotiated SALE: \\ EVIDENCE FROM REAL EsTATE SALES
}

\begin{abstract}
We offer a theoretical and empirical comparison of auctions and negotiated sales. We first build a simple model to show that auctions generate a higher relative price than negotiated sales when demand for the asset is strong, when the asset is more homogeneous, and when the asset attracts buyers with higher valuations. Using data from property sales in Singapore, we find support for our theoretical predictions that the auction mechanism obtains a higher relative price in an "up market" than in a flat or down market, in the high-end segment of the property market, and for relatively homogeneous properties than heterogeneous properties.
\end{abstract}

Keywords: Auction, Negotiated Sale, Market Conditions, Product Homogeneity, Foreclosure

*Contact Author: Department of Real Estate, National University of Singapore, 4 Architecture Drive, S(117566), Singapore. Email: yuenleng@nus.edu.sg, Tel: +65-65161284, Fax: +65-67748684. 


\section{Introduction}

Standard auctions are deemed to be the revenue-maximizing methods of sale when bidders are assumed to hold independent private valuations, are ex-ante identical, and exhibit symmetric bidding strategies (Bulow and Klemperer 2009; Campbell and Levin 2006; Wang 1993; McAfee and McMillan 1988). Auctions are favored in practice when the good sold is unique or nonstandardized, infrequently traded or has a "thin" market, or the good's price is not easily determined (Milgrom 1989; Cassidy 1967). Examples of unique goods include rare art pieces, diamonds, and vintage wine. Real estate, given its characteristics (products are heterogeneous ${ }^{1}$ and high-value real estate tends to be infrequently traded, leading to price uncertainty in the market), seems to be well suited to be sold through auction. Yet, the dominant selling mechanism for real estate is through brokered or negotiated sales. In the US real estate market, auctions are rarely used, ${ }^{2}$ except for foreclosed or distressed properties. In this instance, the auction mechanism is chosen not because of its revenue-maximizing feature but for its ability to minimize the property's holding $\operatorname{costs}^{3}$ and to expedite the recovery of the mortgage loan.

The literature tends to look at the problem of the optimality of the sales mechanism from the buyers' and sellers' perspectives and implicitly assumes the product to be homogeneous. This paper looks at the same question but with an emphasis on the impact of the asset and market characteristics on the choice of sales mechanism. First, we build a simple theoretical model to compare expected revenue under auctions and negotiated sales. We then compare the

\footnotetext{
${ }^{1}$ Each piece of real estate is unique. Even apartment units, which can be almost identical in terms of number of rooms and floor area, are still unique in terms of which floor they are located on, which direction they face, etc.

${ }^{2}$ In Australia and New Zealand, auctions are widely used to sell properties. Reed et al. (2002) note that in Melbourne, approximately $75 \%$ of residential properties are sold through auction.

${ }^{3}$ Quan (2002) reports that the annual holding cost for commercial property can be up to $20 \%$ of the property's appraised value. In the residential market, listed properties may take three months before being sold by an agent, whereas the auction process only requires a month.
} 
performance of the two sales mechanisms empirically, using transaction prices for properties sold in Singapore. Our aim is to establish whether a gap exists between the two sales mechanisms, that is, whether the same asset sells for the same sale price under the two different mechanisms. If such a gap exists, we then investigate how it varies with the characteristics of the property and across different market conditions.

Studies by Quan (2002), Mayer (1995, 1998), and Lusht (1996) examine price differences between auction and negotiated sale mechanisms by utilizing property sales data from the United States, Australia, and New Zealand, respectively. As will be described in detail in the next section, these studies arrive at different conclusions. In the literature relating to business acquisitions, the results are also mixed as to whether auctioning off a company or selling it through a sequential process is more profitable (Bulow and Klemperer 1996, 2009; Thomas and Wilson 2002; Boone and Mulherin 2007). Studying the price difference in relation to product types, Wang (1993) and Bulow and Klemperer (2009) consider auctions to generate higher revenue when the asset (bidders' values) has higher price dispersion. With regard to price differences across market conditions, Bulow and Klemperer (1996) conclude that auctions perform better when there are more bidders, Boone and Mulherin (2007) find the wealth effects for target shareholders to be comparable in auctions and negotiations, and Thomas and Wilson (2002) find prices to be higher in multilateral negotiations when the number of sellers is small.

The contribution of this study to the existing literature is twofold. First, we offer a simple theoretical model to study the price differential between the two sales mechanisms. Second, we provide a detailed empirical investigation of whether the two sales mechanisms perform consistently across different property types and market conditions. The empirical results may yield intuitive insights that help explain the choice of selling mechanism. The data set comprises 
both successful and unsuccessful auction attempts of foreclosed and non-foreclosed residential real estate in Singapore over a period of 10 years, covering three different market periods (up, down, and flat markets). The range of property types covers relatively homogeneous properties (apartments) as well as more heterogeneous properties (terrace, semi-detached, and detached houses $^{4}$ ). Overall, our results show that properties obtain a higher price when sold through auction than through negotiated sales. However, this premium is not consistent across property types and market conditions. As predicted by our theoretical model, we find that auctions enjoy a higher price premium in markets where demand is stronger and for higher-valued properties. We also find that homogeneous properties have a higher percentage price differential than heterogeneous properties. In addition, we find that auctions generate a higher price for foreclosed properties than for non-foreclosed properties.

The rest of the paper is structured as follows: Section 2 provides a general overview of the differences between auction and negotiated sales and reviews papers that compare the performance of these two mechanisms. Section 3 offers a simple theoretical model to study the relative attractiveness of the two mechanisms under various parameterized market conditions. Section 4 discusses the methodology, and Section 5 describes the data. Section 6 presents the empirical results, and finally, Section 7 offers concluding remarks.

\footnotetext{
${ }^{4}$ To map these property types to the US residential market: terrace houses are a row of two-storey townhouses, semi-detached are two units of adjoining townhouses, and detached houses are single-family dwellings. It is important to note that auctions are commonly used to sell real estate in Singapore, both for foreclosed and nonforeclosed property. This is different from the US where auctions are typically used only to sell foreclosed properties.
} 


\section{Background and Literature Review}

\subsection{Differences between Auctions and Negotiated Sales}

In the real estate market, the critical difference between auctions and negotiated sales lies in the timing and comparison of the offers. In negotiated sales, buyers go through a search process to find the "right" property, while sellers go through a search process to find the buyer who is willing to pay at least the seller's reservation price. Through the search process, the seller

receives and evaluates offers sequentially. The seller has the option to solicit additional offers if initial offers are unsatisfactory. However, this process does not allow the seller to compare offers, as offers do not arrive simultaneously and expire if not accepted within a certain period of time. The auction, by contrast, acts as a centralized marketplace for the seller to solicit offers at one time, and allows the seller to compare all the offers available at that time. If at least one bid meets the reservation price, the sale can proceed immediately.

Bulow and Klemperer (2009) identify four factors that may explain why auctions generate higher revenue for sellers than sequential mechanisms, when entry is costly. These four factors are (i) number of potential bidders; (ii) bidders" ability to make "jump bids" in the search market may drive buyers' profits to zero, whereas bidders' ability to make "jump bids" in auction market may drive buyers' profits into negative numbers; (iii) more dispersed bidder values for auctions; and (iv) the gap between expected winning values and expected revenue. According to Bulow and Klemperer (2009), the most critical factor is that bidders' values are more dispersed for auctions, making the auction a less informationally efficient mechanism than sequential sales, which have less dispersed bidders' values. Sellers will be able to capitalize on this relative information inefficiency to earn higher revenue. 
Milgrom (1987) argues that the auction is a popular selling mechanism over a wide range of circumstances because auctions lead to stable and efficient allocation outcomes. The auction, through the competitive bidding process, enables a seller in a weak bargaining position to do as well as a seller in a strong bargaining position. Arnold and Lippman (1995) prove theoretically that if a seller is selling a small number of identical items, he will obtain a higher per-unit return from the sequential sales mechanism. However, if a seller is selling a large number of items, the cost savings accruing from selling all items at the same time yield a better per-unit return. Thus, the value of higher negotiation or bargaining strength is small compared to the value of using competition among the bidders to drive prices up (Bulow and Klemperer 1996). Thomas and Wilson (2002) argue that a buyer's ability to credibly reveal rival offers to sellers influences the revenue obtained from two different mechanisms - multilateral negotiations and first-price auctions. If information on rival bids is not credible, the favorable negotiation position of one party may result in negotiated prices being higher than auction prices. In the experiments they conduct,, Thomas and Wilson (2002) find that prices are indistinguishable between multilateral negotiations and auctions when there are four sellers, but higher in multilateral negotiations when there are two sellers. Wang (1993) compares posted-price selling against auctions and concludes that auctions are preferred to posted-price selling when the value of the object is more dispersed $^{5}$ and for items with higher value. Hence, whether auction or negotiated sales is a better mechanism varies according to the parameters of the sale, including the number of objects auctioned and the distribution of valuations.

Quan (2002) focuses on the difference in the timing of offers between the two sales mechanisms. He points out that in real estate, the transaction, search, and holding costs are high.

\footnotetext{
${ }^{5}$ For Wang (1993), dispersion refers to the variance around the mean value of the item.
} 
A buyer's reservation price and expected benefit from search are influenced by the search costs. Thus, a buyer with high search costs attends auctions. Conversely, a buyer with low search costs has a higher payoff in the search market. Therefore, since high-search-cost buyers attend auctions, prices are expected to be higher for properties sold at auction. On the seller's side, the cost of holding a property will influence the number of properties put up for auction. Mayer (1995) also compares the performance of real estate auctions with negotiated sales, and develops a theoretical model that explains the observed discounts in auction markets and why they increase in a down market. In an auction, the buyer's valuation is based on alternatives expected to be available in the search market. With more vacancies, the search alternative offers better choices, resulting in an increase in the auction discount. The existence of more buyers, on the other hand, increases the effectiveness of the auction method and leads to a decrease in the auction discount.

Empirical studies using real estate data that compare property returns from negotiated sales and auctions present differing results. Ashenfelter and Genesove (1992) document that condominium units in New Jersey sold through negotiated sale after an unsuccessful auction process are sold at a $13 \%$ discount. ${ }^{6}$ Lusht (1996) finds that properties auctioned in the Melbourne, Australia housing market sell on average for about $8 \%$ more than properties sold through negotiated sales. Mayer (1998) finds that compared to the market price index, properties auctioned in Los Angeles sell at an estimated discount of $0 \%-9 \%$, while properties auctioned in

\footnotetext{
${ }^{6}$ The results from Ashenfelter and Genesove (1992) need to be interpreted with care. Buyers of the unsold units were registered but not the unsuccessful bidders from the auction. These buyers may have an informational advantage regarding the "common value" (hammered down auction price) and might have a good guess about the level of competing demand for these units. Therefore, they are probably going to use this information to their advantage in subsequent negotiations. In addition, these unsold units may be "burned" - when an advertised item is not sold, its future value will be affected (Ashenfelter 1989). Theoretically, this point will not matter if buyers hold independent valuations. However, the authors state that some of the buyers were purchasing for investment purposes; hence the common value assumption may apply and the issue of unsold units being "burnt" may become relevant.
} 
Dallas sell at an estimated discount of 9\% - 21\%. Dotzour, Moorhead, and Winkler (1998) find mixed results in their analysis of the housing market in Christchurch, New Zealand. Their results indicate that highly priced, unique, and desirable houses achieve a 5.9\% - 9.5\% premium when sold through auction, while houses in the other two areas under study show no premium or discount between auction and private-treaty sales.

\subsection{Other Considerations in the Choice of Sales Mechanism}

Quan (2002) argues that when buyers and sellers are free to choose the selling mechanism, holding and transaction costs determine the market participant's choice of mechanism. Engelbrecht-Wiggins (1996) presents a model whereby a seller of multiple units of a good sells some units non-competitively (via any sales technique besides an auction) and some units through an auction. He argues that such a mix of auction and non-competitive sales benefits the seller and increases market efficiency because some buyers may not participate in an auction due to high participation costs. These costs may be in the form of information-gathering costs to establish the market value of the object. Engelbrecht-Wiggins's (1996) insight is also applicable to the real estate market. Usually, participants in the residential property market are one-off buyers and sellers, and may face high information costs related to researching how the property markets work, finding out about the sales procedures, investigating the prevailing market values of similar properties in a particular locale, and determining what properties are available in the market. Boone and Mulherin (2007) consider the agency costs and information costs of takeovers. They find that the wealth effects for target shareholders are comparable in auctions and negotiations. 
In a theoretical study, Wang (1993) uses variations in the distribution of buyers' valuations to determine whether sellers prefer auctions to selling at a posted price. Wang (1993) considers the circumstances in which a seller chooses to auction an object rather than selling it at a fixed price. The author finds that if there is a relatively wide dispersion in the distributions of buyers' valuations, the seller prefers to wait longer in order to have more bidders participating in the auction. Over time, the distribution of the second-highest bid shifts upward and the seller is likely to get a higher sales price. Wang (1995) compares bargaining to posted-price selling and concludes that for objects that are difficult to value (i.e., when buyers' valuations are dispersed), sellers prefer bargaining to posted-price selling.

The choice of sales mechanism may also be influenced by the characteristics of the product being sold. Bajari, McMillan, and Tadelis (2003) examine how building contracts are awarded in Northern California. They find that auctions perform poorly when the building design is complex. In addition, they find that the use of auctions is countercyclical. During a construction boom, few contractors are willing to bid for projects. This low participation erodes the competitive bidding advantage accruing to an auction. Helstad, Vassdal, and Trondsen (2005) examine the use of auctions and negotiated sales in the sale of fish in North Norway. Their study indicates that more homogeneous lots are typically sold by auction, whereas more heterogeneous lots are typically sold by negotiated sales. They also find that frozen fish sold through auction obtain the highest sales price, although auction sales also exhibit larger monthly variation in prices. Kulger, Neeman, and Vulkan (2006) find that a centralized market is more advantageous to "high-value" traders of homogeneous goods. In their study, "high-value traders" are buyers who have a high willingness to pay and sellers who have low reservation prices. Using an experimental methodology, the authors find support for their hypothesis. 
In the next section, we build a simple theoretical model to compare the expected revenue of the two sales mechanisms and how revenue relates to such factors as the number of bidders, homogeneity of the asset, and the distribution of buyers' valuation of the asset.

\section{A Simple Model}

Consider a risk-neutral seller who wants to sell her house. The seller's valuation of the house is normalized to 0 . There are $n$ symmetric potential buyers who draw their private valuations for the house independently from a distribution $\mathrm{F}$ over the interval $[0, w]$. We compare two selling mechanisms. The first mechanism, auctions, involves auctioning the house right away. The second mechanism, negotiated sales, involves two stages. In the first stage, the seller announces a list price and offers the unit at this list price. Any buyer can purchase the house at the list price (if there is more than one willing buyer, the house is allocated randomly to one of those buyers). If no buyer purchases the house at the list price, then in the second stage the seller conducts an auction and sells the unit to the buyer with the highest offer at the price equal to his bid.

We first analyze the revenue from auctions. The revenue from a standard auction is well known:

$$
\begin{aligned}
\pi^{A} & =E\left[Y_{2}^{(n)}\right] \\
& =\omega-\int_{0}^{\omega} F_{2}^{(n)}(y) d y
\end{aligned}
$$

where $Y_{2}^{(n)}$ is the random variable that represents the second highest of $n$ independent draws, and $F_{2}^{(n)}$ is its distribution with

$$
F_{2}^{(n)}(y)=F(y)^{n}+n F(y)^{n-1}(1-F(y))
$$


(see Krishna 2002, Chapter 2.4).

Revenue from the negotiated sales mechanism is more complicated. For any list price $l$ in the relevant range, in equilibrium only buyers whose valuations are higher than a certain value, $c$, would want to buy the house in the first stage, ${ }^{7}$ other buyers would wait for the second stage. In equilibrium, the buyer with value $c$ should be indifferent between obtaining the object in the first stage and waiting for the second stage.

The expected payoff by claiming the object in the first stage is given by

$$
(c-l) p
$$

where $p$ is the probability of winning and is given by ${ }^{8}$

$$
p=\sum_{k=0}^{k=n-1} \frac{1}{k+1}\left(\begin{array}{c}
n-1 \\
k
\end{array}\right) F(c)^{n-1-k}(1-F(c))^{k}
$$

The expected payoff from participating in the second stage is given by

$$
\delta \int_{0}^{c}(c-y)(n-1) F(y)^{n-2} f(y) d y
$$

where $\delta<1$ is the discount factor and $(n-1) F(y)^{n-2} f(y)$ is the density of the highest value among competitors. This expression is written for a second-price auction in the second stage, and by the revenue equivalence principle it is the expected payoff for all efficient mechanisms. ${ }^{9}$

Hence, the critical buyer valuation $c$ would be determined by equating

\footnotetext{
${ }^{7} \mathrm{C}$ is a function of $l$, but we suppress it for ease of notation.

${ }^{8} \mathrm{Here}$, we assume that the buyers decide simultaneously whether or not they would like to buy the house in the first stage.

${ }^{9}$ More precisely, it is the expected payoff for all the efficient mechanisms in which the lowest value participant obtains zero expected payoff.
} 


$$
(c-l) p=\delta \int_{0}^{c}(c-y)(n-1) F(y)^{n-2} f(y) d y
$$

By setting a list price $l$, the seller's overall expected payoff is given by

$$
\left(1-F(c)^{n}\right)+\delta F(c)^{n}\left[c-\int_{0}^{c} F_{2, l}^{(n)}(y) d y\right]
$$

where

$$
F_{2, l}^{(n)}(y)=\left(\frac{F(y)}{F(c)}\right)^{n}+n\left(\frac{F(y)}{F(c)}\right)^{n-1}\left(1-\frac{F(y)}{F(c)}\right)
$$

Hence, the seller would choose $c^{*}$ to maximize

$$
\left(1-F(c)^{n}\right)+\delta\left(F(c)^{n} c-\int_{0}^{c}\left(F(y)^{n}+n F(y)^{n-1}(F(c)-F(y))\right) d y\right)
$$

where, from equations (4) and (6) above,

$$
l=c-\frac{\delta \int_{0}^{c}(c-y)(n-1) F(y)^{n-2} f(y) d y}{\sum_{k=0}^{k=n-1} \frac{1}{k+1}\left(\begin{array}{c}
n-1 \\
k
\end{array}\right) F(c)^{n-1-k}(1-F(c))^{k}}
$$

Thus, the expected selling price from the negotiated sale mechanism is given by

$$
\left(1-F\left(c^{*}\right)^{n}\right)^{*}+\left(F\left(c^{*}\right)^{n} c^{*}-\int_{0}^{c^{*}}\left(F(y)^{n}+n F(y)^{n-1}\left(F\left(c^{*}\right)-F(y)\right)\right) d y\right)
$$

We compare the two sales mechanisms by examining the expected selling price ratio between auction sales and negotiated sales. To simplify, we assume buyers' valuations are 
uniformly distributed between 0 and $1, F=U[0,1]$.

The expected revenue from the auction mechanism can be expressed as

$$
1-\int_{0}^{1}\left(y^{n}+n y^{n-1}(1-y)\right) d y=\frac{n-1}{n+1}
$$

For the negotiated sales, the list price simplifies to

$$
\begin{aligned}
l & =c-\frac{\delta \int_{0}^{c}\left((c-y)(n-1) y^{n-2}\right) d y}{\sum_{k=0}^{k=n-1} \frac{1}{k+1}\left(\begin{array}{c}
n-1 \\
k
\end{array}\right) c^{n-1-k}(1-c)^{k}} \\
& =c-\frac{\delta \frac{c^{n}}{n}}{\sum_{k=0}^{k=n-1} \frac{1}{k+1}\left(\begin{array}{c}
n-1 \\
k
\end{array}\right) c^{n-1-k}(1-c)^{k}} .
\end{aligned}
$$

The seller would choose $c$ to maximize

$$
\begin{aligned}
& \left(1-c^{n}\right) l+\delta\left(c^{n+1}-\int_{0}^{c}\left(y^{n}+n y^{n-1}(c-y)\right) d y\right) \\
= & \left(1-c^{n}\right) l+\delta \frac{n-1}{n+1} c^{n+1}
\end{aligned}
$$

or

$$
\left(1-c^{n}\right)\left(c-\frac{\delta \frac{c^{n}}{n}}{\sum_{k=0}^{k=n-1} \frac{1}{k+1}\left(\begin{array}{c}
n-1 \\
k
\end{array}\right) c^{n-1-k}(1-c)^{k}}\right)+\delta \frac{n-1}{n+1} c^{n+1}
$$

The expected selling price from the negotiated sale mechanism can now be written as 


$$
\left(1-c^{n}\right)\left(c-\frac{\delta \frac{c^{n}}{n}}{\sum_{k=0}^{k=n-1} \frac{1}{k+1}\left(\begin{array}{c}
n-1 \\
k
\end{array}\right) c^{n-1-k}(1-c)^{k}}\right)+\left.\frac{n-1}{n+1} c^{n+1}\right|_{c=c^{*}}
$$

We can now state the ratio of the expected price under an auction to the expected price under negotiated sale as:

$$
r=\frac{\frac{n-1}{n+1}}{\left(1-c^{n}\right)\left(c-\frac{\delta \frac{c^{n}}{n}}{\sum_{k=0}^{k=n-1} \frac{1}{k+1}\left(\begin{array}{l}
n-1 \\
k
\end{array}\right) c^{n-1-k}(1-c)^{k}}\right)+\left.\frac{n-1}{n+1} c^{n+1}\right|_{c=c^{*}}}
$$

The seller's expected price from the auction mechanism is higher than the negotiated sale mechanism if the above ratio is greater than 1. Otherwise, the negotiated sale yields a higher expected price.

How does the expected price ratio vary with such factors as the number of buyers/bidders in the market and the distribution of their valuations? Because of the complexity of the above expression, we cannot explicitly determine how the price ratio $r$ changes with such factors. For this, we simulate the model above. We start with the impact of the number of bidders, $n$, on the price ratio. Given that a typical auction in our data set involved 2-3 bidders, occasionally reaching 5-7 bidders, we simulate the price ratio for $n=2$ to $n=10$, under four different discount rates, $\delta=0.95 ; \delta=0.90 ; \delta=0.85$; and $\delta=0.7$. Table 1 summarizes the optimal $c$ and the ratio of the auction price to the negotiated sales price under these parameter values. ${ }^{\mathbf{1 0}}$

\footnotetext{
${ }^{10}$ Note that the price ratio of $r<1(r>1)$ does not necessarily mean that negotiated sale is (not) preferred over auction. The price ratio $r$ is the ratio of the two prices, not the expected payoffs to the seller. The ratio $r$ is the ratio of the prices observed by the econometrician and does not distinguish between first- and second-period sale prices (whereas expected utility expression does).
} 
Table 1 about here

The results of the simulations yield the following testable prediction:

Hypothesis 1: When the demand in the market is stronger, i.e., when the number of bidders/buyers in the market is larger, the expected selling price under the auction mechanism becomes relatively higher than under the negotiated sale mechanism.

We next calibrate the price ratio for different segments of buyers' valuations. The purpose of this calibration is to study how the price ratio changes for high-end versus low-end markets and how it varies with the range of the distribution. The results are illustrated in the graph below. We divided the distribution of buyers' valuations into three segments: $[0, a],[a, b]$, and $[b, 1]$. To keep the lower and upper quantiles symmetric, we set $b=1-a$. An increase in $a$ has the following effect for the three quantiles: both the mean and the range of valuations of the lower quantile increase; the mean of the upper quantile decreases while the range of valuations of the upper quantile increases; the mean of the middle quantile remains the same while the range of valuations of the middle quantile becomes smaller. As an example, consider $a=0.3$. The three ranges of valuations become $[0,0.3],[0.3,0.7]$, and $[0.7,1]$, and the corresponding price ratio of the two sale mechanisms for the three quantiles are obtained as $0: 99525 ; 1: 0063$; and 1:0114.

Figure 1 about here 
One can interpret the three quantiles as proxies for the lower, middle, and upper ends of the market. Alternatively, the lower quantile could represent a down market, the middle quantile a flat market, and the upper quantile an up market. As illustrated in the graph, the price ratio is lowest for the lower quantile for all $a$ values, and it is lower for the middle quantile than for the upper quantile for $a \leq 0.37$. In our empirical analysis, we divide the market into three quantiles using $a=0.3$. The results of the calibrations yield the following testable hypothesis:

Hypothesis 2: For $a=0.3$, the ratio of the expected price from an auction to that of negotiated sale is highest in the upper quantile of the market, followed by the middle and lower quantiles of the market.

Finally, the range of a quantile can serve as a proxy for the homogeneity of the product. One would expect the range of valuations for a more homogeneous product to be narrower. Of particular interest in the graph above is the middle quantile $[a, 1-a]$, as a decrease in $a$ in this quantile is a mean-preserving spread in the distribution of valuations in that quantile. Thus, an asset with a higher value of $a$ in the middle quantile can be interpreted as a more homogeneous asset. The calibration results depicted in the graph above yield our third testable hypothesis:

Hypothesis 3: The ratio of the expected price from an auction to that of negotiated sale is higher for more homogeneous units. 
Note that the same result also holds for the lower and upper quantiles, where an increase in $a$ represents a non-mean-preserving spread in the distribution of valuations.

We next discuss our empirical methodology and the data set.

\section{Methodology}

Given that buyers and sellers are free to choose whether to participate in an auction or a negotiated sale market, any comparison of the two sales mechanisms has to account for sample selectivity bias. In the United States, auctions are used almost exclusively for distressed properties. However, in Australia, New Zealand, and Singapore, auctions are widely accepted and are used to sell both desirable properties as well as distressed properties.

A question of primary interest in this paper is whether there is a price premium or discount if the same property is sold through auction versus negotiated sale. The choice made by the seller between the two sale mechanisms represents the trade-off between an expedient sale and waiting for an offer that will meet or even exceed the seller's reservation price. The rational seller will choose the method that maximizes the expected returns. At the same time, this choice also implies that the sample of properties sold through different sales mechanisms is not random. Thus, we need to check for, and if needed, correct for sample selection bias. ${ }^{\mathbf{1 1}}$ If this bias is not accounted for in the pricing equations, the estimates for the coefficients will not be consistent.

\footnotetext{
${ }^{11}$ The significance of selectivity bias is illustrated by Quan (2002). Using U.S. data, Quan (2002) finds that if the choice of sales mechanism is not treated as an endogenous variable, property prices will decrease if sold by auction. However, when the endogeneity is accounted for, property prices increase by 30 percent if sold by auction. Lusht (1996), using Australian data, did not find evidence of sample selection bias between auction sales and negotiated sales. These studies suggest that it is important to check whether properties or sellers with certain characteristics are more prone to choose one sales mechanism over the other.
} 
Following the structure of the empirical model of Lee (1978), we use the two-step estimation procedure suggested by Heckman $(1976,1979)$ to estimate our price equations for the two sales mechanisms. The selection equation that models the seller's choice of mechanism is estimated using a Probit model:

$I_{i}^{*}=\gamma_{0}+\gamma_{1} X_{i}^{\prime}+\gamma_{2} M_{i}^{\prime}+\gamma_{3} Z_{i}^{\prime}-\varepsilon^{*}$

where $I_{i}=1$ if the property is sold through an auction and $I_{i}=0$ if the property is sold through negotiated sale. The variables $X_{i}$ and $M_{i}$ are observable exogenous variables. $X_{i}$ is a vector of property characteristics that includes property types, geographical location, property tenure, floor area, and a dummy vector that indicates whether the property is foreclosed. $M_{i}$ is a vector of property market conditions and is proxied by the property price index. $Z_{i}$ is a vector of qualitative variables that proxy for factors that influence the seller's choice of sales mechanism. The three variables in vector $Z_{i}$ are: number of prior unsuccessful auction attempts, presence of bidders bidding in the preceding auction attempt, and the number of days since the last auction attempt. All three variables are expected to influence whether the seller chooses to sell via negotiated sale or auction, but none directly influences the selling price of the property. As a result, $Z_{i}$ is present in the selection equation but not in the price equations below.

From the Probit model, we derive the inverse Mill's ratio to determine whether selectivity bias is present. Thus, the pricing equations conditional on the chosen sales mechanism are:

logprice $_{a i}=\theta_{a 0}+X_{a i} \theta_{a 1}+M_{a i} \theta_{a 2}+\sigma_{a i \varepsilon}\left(-\frac{f\left(\Psi_{i}\right)}{F\left(\Psi_{\mathrm{i}}\right)}\right)+\eta_{a}$, 
logprice $_{n s i}=\theta_{n s 0}+X_{n s i} \theta_{n s 1}+M_{n s i} \theta_{n s 2}+\sigma_{n s i \varepsilon}\left(-\frac{f\left(\Psi_{i}\right)}{F\left(\Psi_{\mathrm{i}}\right)}\right)+\eta_{n s}$,

where $E\left(\eta_{a} \mid I_{i}=1\right)=0$ and $E\left(\eta_{n s} \mid I_{i}=0\right)=0$.

where logprice ${ }_{a i}$ is the natural logarithm of the transacted price when property $i$ is sold through an auction and logprice ${ }_{n s i}$ is the natural logarithm of the transacted price when property $i$ is sold through a negotiated sale. Let $I_{i}$ be a binary dummy that represents an auction sale when $I_{i}=1$ and a negotiated sale when $I_{i}=0$. Thus, we observe price $_{a i}$ when $I_{i}=1$ and price $_{n s i}$ when $I_{i}=0$.

Using these estimated pricing equations conditional on the sales mechanism chosen, we further obtain the estimated price difference for the same property when sold through the alternative sales mechanism. For property $i$, the estimated auction price and estimated negotiated sale price are:

$\hat{\mu}_{a i}=\hat{\theta}_{a 0}+X_{a i} \hat{\theta}_{a 1}+M_{a i} \hat{\theta}_{a 2}$,

$\hat{\mu}_{n s i}=\hat{\theta}_{n s 0}+X_{n s i} \hat{\theta}_{n s 1}+M_{n s i} \hat{\theta}_{n s 2}$.

Following the formula provided by Lee (1978), we calculate the percentage price differential for property $i$ sold under auction versus negotiated sale as:

PctDiff $f_{i}=\frac{\exp \left\{\widehat{\theta}_{a 0}+X_{a i} \widehat{\theta}_{a 1}+M_{a i} \widehat{\theta}_{a 2}\right\} \exp \left\{\frac{1}{2}\left(\widehat{\sigma}_{a i}^{2}-\widehat{\sigma}_{n s i}^{2}\right)\right\}-\exp \left\{\widehat{\theta}_{n s 0}+X_{n s i} \widehat{\theta}_{n s 1}+M_{n s i} \widehat{\theta}_{n s 2}\right\}}{\exp \left\{\widehat{\theta}_{n s 0}+X_{n s i} \widehat{\theta}_{n s 1}+M_{n s i} \widehat{\theta}_{n s 2}\right\}}$, 
where $n$ is the number of observations in the sample, $\hat{\sigma}_{a i}^{2}$ is the standard errors from the estimated auction price equation, and $\hat{\sigma}_{n s i}^{2}$ is the standard errors from the estimated negotiated sales equation.

In this paper, we are also interested in whether this price differential between the two sales mechanisms is constant across different price segments. We subdivide our data into three quantiles using the ratio $0.3,0.4$, and 0.3 . The lowest $30^{\text {th }}$ percentile corresponds to the low-end property market, the highest $30^{\text {th }}$ percentile corresponds to the high-end property market, and the middle 40 percent corresponds to the middle-priced property market. To further examine the price differential, we run the following regression:

PctDiff $_{i}=\beta_{0}+\beta_{1} P V_{i}+\beta_{2} S M_{i}+\beta_{3} F C_{i}+\varepsilon$

where $P V_{i}$ is the price variance ${ }^{\mathbf{1 2}}$ of the transacted price of property $i$ that measures the deviation of the transacted price of property $i$ from typical price levels in the sample, $F C_{i}$ is a dummy variable indicating whether property $i$ was sold as a foreclosed property, and $S M_{i}$ is a dummy

$12 \mathrm{We}$ adopt the Mahalanobis approach to measure the covariance-adjusted differences in the transacted price of property $i$ from typical price levels in the data sample. Our price variable is computed as follows:

$$
\begin{gathered}
\text { DPVar }{ }_{\text {homo }, i l}^{2}=\left(\text { PVar }_{\text {homo }, i l}-\overline{P V a r}_{\text {homo }, i l}\right)^{\prime} C_{w}^{-1}\left(\text { PVar }_{\text {homo }, i l}-\overline{\text { PVar }}_{\text {homo }, i l}\right) \\
\text { DPVar }{ }_{\text {hetero }, j l}^{2}=\left(\operatorname{PVar}_{\text {hetero }, j l}-\overline{P V a r}_{\text {hetero }, j l}\right)^{\prime} C_{w}^{-1}\left(\text { PVar }_{\text {hetero }, j l}-\overline{\text { PVar }}_{\text {hetero }, j l}\right)
\end{gathered}
$$

where DPVar homo,il measures the squared covariance-adjusted distance to the group mean of the estimated prices of homogeneous properties located in planning region $l$. DPVar hetero,jl measures the squared covariance-adjusted distance to the group mean of the estimated prices of heterogeneous properties located in planning region $l$. $P V a r_{\text {homo } i l}$ refers to the vector of estimated sales prices (auction and negotiated sales prices) for homogeneous property $i$ located in region $l$. $P V a r_{\text {hetero,jl }}$ refers to the vector of estimated sales prices for property $j$ located in region l. $\overline{P V a r}_{\text {homo,il }}$ refers to the group mean of the vector of estimated sale prices for homogeneous properties located in planning region $l$. $\overline{P V a r}_{\text {hetero, } j l}$ refers to the group mean of the vector of estimated sale prices for heterogeneous properties located in planning region $l$. $C_{w}^{-1}$ refers to the inverse of the pooled within-group covariance matrix of the vector of estimated sale prices PVar. The Mahalanobis distance is calculated by setting $D P V a r_{\text {homo }, i l}^{2}=$ DPVar ${ }_{\text {hetero }, j l}^{2}$ and then solving for PVar. 
variable indicating the state of the property market at the time of sale of property $i$. There are three states of the market: up, down, and flat.

\section{Data}

The data were compiled by the Singapore Institute of Surveyor and Valuers (SISV) and track the sales status of residential properties from their first sales listing in the database to the point of successful sale. The data contain information on attempted auction sales ${ }^{13}$ by sellers and record the transacted prices and method of sale when a property was sold. The data used in the empirical models consist of 3,022 successful sales transactions over the period 1995Q3 to 2006Q4, of which 777 observations are auction sales and the remaining 2,245 observations are negotiated sales. Since the research question is focused on the impact of sales mechanism on property prices, only successful sales transactions are used as observations in the data set. Table 2 lists the variables used in the empirical models.

\section{Table 2 about here}

The variables used to proxy for the property characteristics are property type, geographical location, property tenure, floor area, and a dummy variable indicating whether the property is under foreclosure. There are four main property types: apartments (dum_apt), terrace (dum_ter), semi-detached (dum_sd), and detached houses (dum_det).

\footnotetext{
${ }^{13}$ In Singapore, property auctions are organized by property consultancies. The property consultancies will hold their own centralized-site auction, bunching properties to sell on the same day and in the same location.
} 
The geographical location is assigned according to the planning regions as set out in the MasterPlan for Singapore. A geographical map is shown in Figure 2. There are five planning regions: Central (dum_pr1), East (dum_pr2), North-East (dum_pr3), North (dum_pr4), and West (dum_pr5). These five planning regions are heavily populated; the whole island is widely serviced by an efficient public transportation system that comprises the subway, light rail, and buses. Out of the five planning regions, land values are highest in the central region because the central business district, downtown core, and high-income residential districts are located there.

Figure 2 about here

The data do not contain information about the age of the property. The best alternative is to use the variable "property tenure." In Singapore, there are two categories of property tenure: freehold and leasehold. An owner of a freehold property, depending on the sale terms, may own the property forever, for 999 years or for 9999 years. For leasehold properties, the 99-year lease starts from the moment a developer purchases the land for development. Upon completion of building (usually 1-2 years later), the developer sells the completed properties to interested buyers. Hence, an owner of a leasehold property in effect only owns the property for less than 99 years. Given these circumstances, the data distribution for property tenure seems better suited as a discrete variable than as a continuous variable. Consequently, in our paper, properties with a remaining lease of 99 years or more are classified as freehold (tenuretype $=1$ ). Properties with a remaining lease of less than 99 years are classified as leasehold (tenuretype $=0$ ). 
The floor area of the property is measured in square feet. Unfortunately, the data collected by SISV do not contain further property characteristics like number of bedrooms and number of bathrooms. However, based on the information available, the independent variables in the pricing equations explain around $78 \%-85 \%$ of the variations in the property prices; hence, the explanatory power of these variables is substantial.

The variable "ppi" represents the property price index. This variable is extracted from ReaLink and is compiled by the Urban Redevelopment Authority (URA). In the data, we correlate the date of sale with the property price index for that quarter. Thus, ppi, as used in our data, helps to capture the state of the real estate market during the time of sale. Figure 3 graphs the movement of the property price index for the period 1995 to 2008, where the base year is 1998. The Singapore property market experienced two peaks (2Q1996 and 2Q2000), a valley (4Q1998), and a relatively long period of flat sales. Based on the shape of the property price index graph, the data are divided into three periods: up market (3Q1995 - 2Q1996, 1Q1999 2Q2002 and 1Q2006 - 1Q2008), down market (3Q1996 - 4Q1998 and 3Q2000 - 4Q2001), and flat market (1Q2002 - 4Q2005).

Figure 3 about here

The variables used to proxy for additional information related to the conditions of sale for the property are: number of auction attempts (aucattempts), whether there are bidders in the previous auction attempt (biddersprev), and number of days since the last auction attempt (tbla). These three variables are the additional variables used in the Probit equation to model the choice of sales mechanism for the property and are not included in the price equations. 
Table 3 presents a summary of the descriptive statistics for the data used here. The first two columns tabulate the mean and median values for the full sample, columns three and four tabulate the values for negotiated sales (NS Props), and columns five and six tabulate the values for auction sales (Auction Props). To test for differences in property characteristics between negotiated sales and auction sales, the nonparametric Wilcoxon rank sum test is applied to test whether the median of the two sub-samples have similar distributions. The Wilcoxon test statistic is tabulated in the last column.

\section{Table 3 about here}

As shown in Table 3, auctioned sales on average obtain a statistically significant higher price than negotiated sales; auctioned sales have a mean value of $\mathrm{S} \$ 1.171$ million, whereas negotiated sales have a slightly lower mean value of $\mathrm{S} \$ 1.151$ million. The average market condition for auctioned sales $($ mean $=118$, median $=116)$ is lower than the average market condition for negotiated sales $($ mean $=120$, median $=115)$. This result seems to imply that more auction sales occur in "poorer" market conditions. For these data, a larger proportion of foreclosed properties is sold through auction $($ mean $=0.80)$ than through negotiated sales (mean $=0.68$ ). A higher proportion of negotiated sales has bidders for the property in the preceding auction attempt $($ mean $=0.09)$ than for auctioned sales $($ mean $=0.05)$. This result implies that sellers may have continued negotiation with the interested bidders after the auction attempt. There is a longer duration between the last auction attempt for properties sold through negotiated sales $($ mean $=105)$ than for auctioned sales $($ mean $=28)$. 
The Wilcoxon tests indicate that in general, properties sold through the two sales methods are not significantly different in terms of property types, location, or size of the properties. However, there are significant differences in terms of price, property location, tenure, and conditions relating to sales choice.

\section{Empirical Results for Choice of Sales Mechanism}

\subsection{Estimated Price Equations}

Table 4 shows the results of the Probit model and estimated price equations for selling through auction and through negotiated sale. Results from the Probit model indicate that property characteristics, by themselves, do not determine the method-of-sale. Rather, other factors like urgency of sale, how long the property was listed on the market, and the state of the property market are statistically significant in explaining the choice of sales mechanism. If the property is foreclosed, the probability that the property will be sold through auction increases by $10 \%$. If there were bidders for the property in the previous auction attempt, the probability decreases by $11 \%$. Each unsuccessful auction attempt also decreases the probability by $3 \%$, and for each day the property remains on the market since the last market attempt, the probability decreases slightly by $0.1 \%$. Compared to when the property market is flat, up- and down-market conditions increase the probability of a property being sold through auction by $10 \%$ and $9 \%$, 
respectively. Property characteristics variables, such as property type, location, size, and land tenure, are statistically insignificant at the 5\% level of significance.

For both pricing equations on Table 4 , the base price equation models the property price for an apartment located in the central region (planning region 1) during a flat-market period. The price equations are estimated using three different methods: (1) Ordinary Least Squares (Model 1); (2) Heckman Two-Step Consistent Estimator (Model 2); and (3) Heckman Maximum Likelihood Estimator (Model 3). In general, the three estimation methods produce similar coefficients, indicating that selectivity bias may not be an issue here. This is supported by the statistically insignificant inverse Mills ratio. Hence, we will use Model 2 to interpret our results in later sections. ${ }^{14}$ Figure 3 traces the property price index over our study period, from which one can observe that the property market has experienced a series of up-market and down-market periods. As explained earlier, we divided the study period into three periods: up market (3Q1995 - 2Q1996, 1Q1999 - 2Q2002 and 1Q2006 - 1Q2008), down market (3Q1996 - 4Q1998 and 3Q2000 - 4Q2001), and flat market (1Q2002 - 4Q2005). Results from the Chow tests for stability in the coefficients show significant differences in the coefficients in the three market periods. For the auction equation, the chi-square statistics are $F(24,741)=2.65$, p-value $=0.000$. For the negotiated sale equation, the chi-square statistics are $F(24,2209)=1.56$, p-value $=0.040$. Thus, we have to use dummy variables to account for differences in the slopes during different market phases.

First, we analyze the empirical results for auction sales. In general, the signs of the various estimated coefficients are as expected. A freehold property obtains a higher sales price than a leasehold property and contributes to a $12.9 \%$ increase in sales price. Compared to

14 Between the two procedures, Greene (2008) states that the Heckman's (1979) two-step estimator is more commonly used. 
properties located in the central region, properties located in the other regions command a lower sales price, and this discount ranges from 3\%-8\%. A 1\% increase in floor area increases property prices by $\$ 2,155,{ }^{15}$ and when the property price index moves up one index point, property prices in the sample increase incrementally by $0.14 \%$. A foreclosed property will obtain a price discount of $2 \%$, but this factor is not significant in explaining price variations in auction sales. Compared to a flat market, property prices are higher in an up market by $7.2 \%$. We note that property type is not significant in explaining the variations in price for auction sales and that terrace, semi-detached, and detached houses obtain lower sales prices than apartments. We do not find support for selectivity bias in the data, as the inverse Mills ratio is statistically insignificant. The independent variables help to explain $72 \%$ of the variations in property prices. The high F-values indicate that all the independent variables help to explain the variations in property prices.

Next, we analyze the empirical results for negotiated sales. In general, the signs of the various estimated coefficients are again as expected. Furthermore, all the independent variables are highly significant in explaining variations in property prices. A freehold property obtains a higher sales price than a leasehold property and contributes to a $7.3 \%$ increase in sales price. Compared to properties located in the central region, properties located in the other regions command a lower sales price, and this discount ranges from 3\%-9\%. A $1 \%$ increase in floor area increases property prices by $\$ 2,029$, and when the property price index moves up one index point, property prices in the sample increase incrementally by $0.26 \%$. A foreclosed property will obtain a price discount of $3 \%$. Compared to a flat market, property prices are higher in an up and down market by $1.4 \%$ and $3.2 \%$, respectively. The finding that property prices are slightly higher

\footnotetext{
${ }^{15}$ This value is obtained by taking the antilog of the exponent of the coefficient.
} 
in a down market than a flat market may seem surprising. The explanation for this result can be seen in Figure 2, where we observe that the property price index is higher in down-market phases (3Q1996 - 4Q1998 and 3Q2000 - 4Q2001) than the flat-market phase (1Q2002 - 4Q2005). For negotiated sales, we find that terrace, semi-detached, and detached houses command higher prices than apartments. This premium ranges from $4 \%-10 \%$. Once again, we do not find support for selectivity bias in the data, as the inverse Mill's ratio is statistically insignificant. The independent variables help to explain $80 \%$ of the variation in property prices. The high Fvalues indicate that all the independent variables help to explain the price variations.

As mentioned, applying the Heckman estimation procedure, we find that the inverse Mills ratios are statistically insignificant in both price equations. In addition, the coefficients of the various explanatory variables are rather stable across the three different estimation models (that is, OLS, Two-Step, MLE). Thus, we can infer that there is no selectivity bias in our data. Looking at the two price equations, the explanatory variables explain $72 \%-80 \%$ of the variations in price and all the signs for the coefficients are as expected. Consequently, using our estimated price equations, we will derive the estimated percentage price differentials for property $i$ when sold through auction versus negotiated sale.

Using estimates from the Probit model, we generate an estimated value for the dependent variable (choice of sales mechanism). Table 5 presents a comparison of the frequency of the actual values with the predicted values. The numbers in the table record the frequency with which the estimated values are matched with the actual values. Overall, we find that about $79 \%$ of the time the estimated values match with the actual values. In addition, the p-values of both the probit model and the price equation models show a high significance level for those 
independent variables that are statistically significant at the 5-10\% level. Consequently, we surmise that the probability of committing a Type II error in our empirical model is low.

Table 5 about here

\subsection{Comparison of Price Differences between Auction and Negotiated Sales}

Table 6 summarizes the derived percentage price differentials for the property $i$, i.e., the estimated percentage price differential when property $i$ is sold through auction versus sold through negotiated sale. The first column "All" shows the percentage differential for the entire data sample, and the next three columns show the percentage differentials for the three market phases. The percentage differentials are analyzed from three angles: whether the property is foreclosed, the property type, and location. The "Max-Min" row of figures indicates the range of the percentage differentials. Hypothesis testing using the Wilcoxon signrank test is applied to determine whether the percentage differential between the two sales mechanisms is statistically significant. ${ }^{16}$ We find that the percentage differentials are statistically significant in all cases except when they are analyzed according to location in a down market.

Table 6 about here

The results show the following general trends. First, properties sold through auction sell for a higher sales price than properties sold through negotiated sales. The percentage price differentials are highest in an up market and lowest in a down market. On average, the

\footnotetext{
${ }^{16}$ Further details pertaining to the number of observations and the z-statistics are available upon request.
} 
percentage differential is $8.2 \%$. In a flat, up, and down market the percentage differentials are $6.6 \%, 11.7 \%$, and $3.7 \%$, respectively. Second, foreclosed properties have a higher percentage differential than non-foreclosed properties, with the biggest difference in value occurring in the down market. In a down market, the percentage differential for foreclosed properties is $5.0 \%$, whereas it is $1.9 \%$ for non-foreclosed properties. Third, in general, apartments obtain the highest

percentage differential of all types of properties. As seen in the "all" column, the percentage differentials for the various property types are: $8.9 \%$ for apartments, $8.4 \%$ for semi-detached houses, $6.9 \%$ for terrace houses, and $5.7 \%$ for detached houses. Given that apartments are generally a lot more homogeneous than other property types, this result supports our theoretical prediction in Hypothesis 3. The widest difference between the percentage differentials of the various property types occurs in a down market. In a down market, the percentage differential for apartments is $5.6 \%$, whereas it is $0.8 \%$ for detached houses. Fourth, there are similar percentage differentials for properties located in the different regions. The range is small, varying from $7.7 \%$ to $9.0 \%$.

\subsection{Empirical Results by Quantiles}

Table 7 presents the regression results for Equation (24), where we regress the estimated percentage differential between the two sales mechanisms on price variance, state of the market, and whether the property was under foreclosure. The base model represents the price spread for a non-foreclosed property that is put up for sale in a flat market. The first column shows the results using the full data sample. The subsequent three columns show more detailed results using different quantiles of the data. Our objective in dividing the data into three quantiles is to 
verify whether the slopes of the regression coefficients change as property values increase. In other words, we wish to see whether the directional relationships between the price spread and these independent variables hold as we progress from the lowest-price property to the highestprice property. Quantile 1 comprises the bottom $30^{\text {th }}$ transacted price percentile of each property type category; quantile 2 comprises the middle $31^{\text {st }}-70^{\text {th }}$ transacted price percentile of each property type category; and quantile 3 comprises the top $30^{\text {th }}$ transacted price percentile of each property type. Henceforth, quantile 1 refers to the low-end property market segment, quantile 2 refers to the middle-priced property segment, and quantile 3 refers to the high-end property market segment.

\section{Table 7 about here}

The dependent variable is the estimated percentage price differential for property $i$ when sold through auction versus negotiated sale. The percentage price difference for property $i$ is calculated based on Equation (23). Thus, it can be interpreted as the percentage price spread between the two sales mechanisms - a positive number indicating a higher price for auction sales and a negative number indicating a lower price for auction sales. Overall, we find that price variance, state of the market (which also acts as a proxy for an increasing number of potential bidders in the auction market), and whether the property was under foreclosure are generally statistically significant in explaining variations in the percentage price spread, at a $5 \%$ level of significance.

On average, we find that auction sales are at least $6.4 \%$ higher than negotiated sales, and this premium increases progressively as we move from the low-end property market to the high- 
end property market (the premium increases from $6.4 \%$ in quantile 1 to $7.4 \%$ in quantile 3 ). This result supports our theoretical prediction stated in Hypothesis 1. Looking at the price variance variable, we note that on average as transacted prices deviate from typical levels by 1 unit, this increased variance causes the percentage price spread to shrink by $1.2 \%$. The shrinkage is highest in the low-end property segment at $2.2 \%$ and smallest in the high-end property segments at $0.3 \%$. Though the price variance variable is statistically significant, we note that the economic impact is negligible on the high-end property segment. Holding other factors constant, we note that the high-end property market suffers the smallest shrinkage in price spread, which also provides support for our Hypothesis 1. The price variance variable is used as a proxy for atypicality (deviations from the typical property unit). As price variance increases for a particular property, this indicates that the property may be more atypical. Generally, for more atypical properties, in a flat market, sellers obtain a better price if they sell their properties through auction rather than negotiated sales. This is in line with earlier results in the literature that auctions are favored for selling unique goods, such as rare art pieces, diamonds, and vintage wine (Milgrom 1989; Cassidy 1967).

Looking at the state-of-the market variables (up market and down market), in line with our theoretical prediction in Hypothesis 1, our results show that sellers obtain a higher expected selling price if they auction off their property in an up market. The competitive pressure of an increase in the number of potential bidders leads to lower bid-shading by bidders in an English auction. Holding other factors constant, auction sales are on average 5.7\% higher than negotiated sale. The middle-priced property segment has the highest auction premium at $5.7 \%$, while the high-end property segment has the lowest auction premium at $4.3 \%$. In a down market, auction sales are on average 1.9\% lower than negotiated sales. The high-end market has the 
highest price spread shrinkage at $4.6 \%$, while the low-end market has the lowest price spread shrinkage at $1.9 \%$. However, the price spread shrinkage for the low-end property segment is not statistically significant. Generally, when the market is unstable, either heading for a boom or a bust, the results indicate that auction sales will benefit sellers of low-end properties more than sellers of high-end properties.

Finally, we find that for properties under foreclosure, auction sales are on average $1.8 \%$ higher than negotiated sales. The high-end property segment has the highest price premium at $2.3 \%$, while the low-end property segment has the lowest price premium at $1.5 \%$. These premiums are statistically significant at a level of $5 \%$. Hence, our results support the conventional practice of auctioning foreclosed properties.

\section{Conclusion}

In this paper, we start with a simple question: "Does the same property sell for the same sale price under different sales mechanisms, specifically, auction versus negotiated sales?" Although this is not a new question in the literature, the answers provided in previous studies vary widely. Mayer $(1995,1998)$ finds that auctioned properties suffer a price discount compared to negotiated sales properties, whereas Lusht (1996) and Quan (2002) find that auctioned properties obtain a price premium. In our paper, we find that the answer to this research question depends on property type and market conditions. Overall, auctioned properties sell for a higher price than negotiated sale properties. More specifically, in general, homogeneous properties (apartments) obtain higher price premiums than heterogeneous properties (terrace, semi-detached, and 
detached houses) when they are sold through auction. Auctions also generate a higher price premium in up markets, for higher end properties, and for foreclosed properties.

In comparing the performance of auction sales and negotiated sales, prior research has focused on such factors as transaction costs, holding costs, and value of the object in the analysis. Our paper extends this line of research by considering the impact of product heterogeneity, market conditions, and market segmentation. Our results illustrate that in deciding whether to sell or buy a property through auction or negotiated sale, a market participant should consider not only holding costs, transaction costs, and value of the property, but also the property characteristics, price segment of the property, and changes in the market conditions. 


\section{References}

1. Arnold, M.A. and S.A. Lippman. 1995. Selecting a Selling Institution: Auction versus Sequential Search. Economic Inquiry 33: 1-23.

2. Ashenfelter, O. and D. Genesove. 1992. Testing for Price Anomalies in Real-Estate Auctions. American Economic Review 82(2): 501-505.

3. Bajari, P., R. McMillan, and S. Tadelis. 2003. Auctions versus Negotiations in Procurement: An Empirical Analysis. NBER Working Paper Series \#9757.

4. Boone, A.L. and J.H. Mulherin. 2007. How are Firms Sold? Journal of Finance 62(2): 847875.

5. Bulow, J. and P. Klemperer. 1996. Auctions versus Negotiations. American Economic Review 86(1): 180-194.

6. Bulow, J. and P. Klemperer. 2009. Why Do Sellers (Usually) Prefer Auctions? American Economic Review 99(4): 1544-1575.

7. Campbell, C.M. and D. Levin. 2006. When and Why Not to Auction. Economic Theory 27: 583-596.

8. Cassady, R. (1967) Auctions and Auctioneering, Berkeley, CA: University of California Press.

9. Dotzour, M.G., E. Moorhead, and D.T. Winkler. 1998. The Impact of Auctions on Residential Sales Prices in New Zealand. Journal of Real Estate Research 16(1): 57-71

10. Ellison, G., M. Mobius, and D. Fudenberg. 2004. Competing Auctions. Journal of European Economic Association 2(1): 30-60.

11. Engelbrecht-Wiggans, R. 1996. Auctions with Noncompetitive Sales. Games and Economic Behavior 16: 54-64.

12. Greene, W.H. 2008. Econometric Analysis, $6^{\text {th }}$ ed., New Jersey: Pearson.

13. Heckman, J.J. 1979. Sample Selection Bias as a Specification Error. Econometrica 47(1): 153-161.

14. Helstad, K., T. Vassdal, and T. Trondsen. 2005. Price Links between Auction and Direct Sales of Fresh and Frozen Fish in North Norway (1997-2003). Marine Resource Economics 20: $305-322$.

15. Krishna, V. 2002. Auction Theory, California, USA: Academic Press. 
16. Kulger, T., Z. Neeman, and N. Vulkan. 2006. Markets versus Negotiations: An Experimental Investigation. Games and Economic Behavior 56: 121-134.

17. Lattin, J., J. D. Carroll, and P. Green. 2003. Analyzing Multivariate Data. Thomson Learning.

18. Lee, L.F. and R.P. Trost. 1978. Estimation of Some Limited Dependent Variable Models with Application to Housing Demand. Journal of Econometrics 8: 357-382.

19. Lee, L.F. 1978. Unionism and Wage Rates: A Simultaneous Equations Model with Qualitative and Limited Dependent Variables. International Economic Review 19(2): 415433.

20. Leffler, K.B., R. Rucker, and I. Munn. 2003. The Choice Among Sales Procedures: Auction v Negotiated Sales of Private Timber, working paper.

21. Lusht, K. 1996. A Comparison of Prices Brought by English Auctions and Private Negotiations. Real Estate Economics 24(4): 517-530.

22. Mayer, C.J. 1995. A Model of Negotiated Sales Applied to Real Estate Auctions. Journal of Urban Economics 38: 1-22.

23. Mayer, C.J. 1998. Assessing the Performance of Real Estate Auctions. Real Estate Economics 26(1): 41-66.

24. Milgrom, P.R. 1987. Auction Theory. Advances in Economic Theory: Fifth World Congress, edited by Truman Bewley, London: Cambridge University Press, 1987, 1-32.

25. McAfee, R.P. and J. McMillan. 1988. Search Mechanisms. Journal of Economic Theory 44: 99-123.

26. Quan, D.C. 1994. Real Estate Auctions: A Survey of Theory and Practice. Journal of Real Estate Finance and Economics 9(1): 23-50.

27. Quan, D.C. 2002. Market Mechanism Choice and Real Estate Disposition: Search Versus Auction. Real Estate Economics 30(3): 365-384.

28. Thomas, C.J. and B.J. Wilson. 2002. A Comparison of Auctions and Multilateral Negotiations. RAND Journal of Economics 33(1): 140-155.

29. Wang, R. 1993. Auctions versus Posted-Price Selling. American Economic Review 83(4): $838-851$. 
30. Wang, R. 1995. Bargaining versus Posted-Price Selling. European Economic Review 39: 1747-1764. 
Table 1: Optimal $c$ and ratio of auction price to negotiated sales price under varying parameter values.

\begin{tabular}{|l|c|c|c|c|c|c|c|c|c|c|}
\hline & & $\mathbf{n = 2}$ & $\mathbf{n = 3}$ & $\mathbf{n = 4}$ & $\mathbf{n = 5}$ & $\mathbf{n = 6}$ & $\mathbf{n = 7}$ & $\mathbf{n = 8}$ & $\mathbf{n = 9}$ & $\boldsymbol{n = 1 0}$ \\
\hline$\delta=0.95$ & $\boldsymbol{c}^{*}$ & 0.787 & 0.837 & 0.863 & 0.879 & 0.891 & 0.900 & 0.907 & 0.913 & 0.918 \\
\hline & $\boldsymbol{r}$ & 0.989 & 0.998 & 1.001 & 1.003 & 1.003 & 1.004 & 1.0045 & 1.0049 & 1.0051 \\
\hline$\delta=0.90$ & $\boldsymbol{c}^{*}$ & 0.736 & 0.793 & 0.824 & 0.844 & 0.860 & 0.871 & 0.880 & 0.887 & 0.895 \\
\hline & $\boldsymbol{r}$ & 0.976 & 0.995 & 1.002 & 1.005 & 1.006 & 1.008 & 1.009 & 1.010 & 1.011 \\
\hline$\delta=0.85$ & $\boldsymbol{c}^{*}$ & 0.705 & 0.765 & 0.799 & 0.821 & 0.838 & 0.851 & 0.862 & 0.870 & 0.878 \\
\hline & $\boldsymbol{r}$ & 0.961 & 0.991 & 1.002 & 1.006 & 1.009 & 1.012 & 1.013 & 1.014 & 1.015 \\
\hline$\delta=0.70$ & $\boldsymbol{c}^{*}$ & 0.653 & 0.715 & 0.752 & 0.779 & 0.798 & 0.814 & 0.827 & 0.837 & 0.847 \\
\hline & $\boldsymbol{r}$ & 0.916 & 0.978 & 0.999 & 1.010 & 1.016 & 1.020 & 1.023 & 1.025 & 1.026 \\
\hline
\end{tabular}


Figure 1: Values of $\boldsymbol{r}$ as a function of $\boldsymbol{a}$

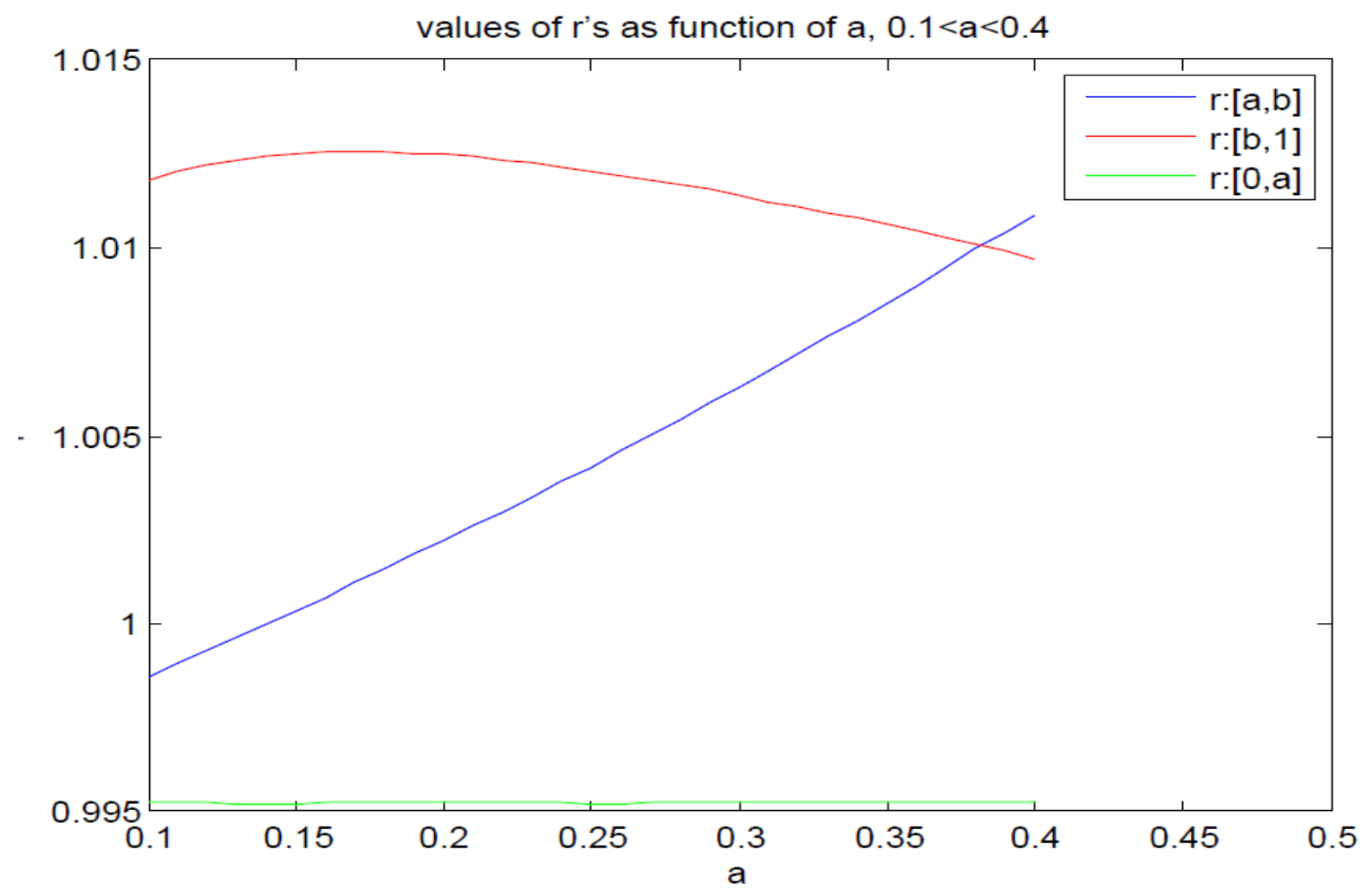


Table 2: Definition of variables in the empirical models

\begin{tabular}{|c|c|}
\hline Variable & Description \\
\hline alogprice & Log selling price of properties sold through auction. \\
\hline nslogprice & Log selling price of properties sold through negotiated sale. \\
\hline $\begin{array}{l}\text { dum_apt } \\
\text { dum_ter } \\
\text { dum_sd } \\
\text { dum_det }\end{array}$ & $\begin{array}{l}\text { Binary dummy variable indicating the type of property sold. } \\
\text { The dummy variable is one if the property is: } \\
\text { dum_apt: apartments or condominium units } \\
\text { dum_ter: terrace houses } \\
\text { dum_sd: semi-detached houses } \\
\text { dum_det: detached houses }\end{array}$ \\
\hline $\begin{array}{l}\text { dum_pr1 } \\
\text { dum_pr2 } \\
\text { dum_pr3 } \\
\text { dum_pr4 } \\
\text { dum_pr5 }\end{array}$ & $\begin{array}{l}\text { Binary dummy variable indicating the geographic location of the property. The location } \\
\text { is organized by planning regions as demarcated in the Singapore Masterplan. The } \\
\text { dummy variable is one if the property is located in: } \\
\text { dum_pr1: Central region } \\
\text { dum_pr2: East region } \\
\text { dum_pr3: North-East region } \\
\text { dum_pr4: North region } \\
\text { dum_pr5: West region }\end{array}$ \\
\hline tenuretype & $\begin{array}{l}\text { Binary dummy variable indicating the land tenure of the property. The dummy variable } \\
\text { has a value of one if the land tenure has a remaining land lease of more } 99 \text { years or more } \\
\text { and zero otherwise. }\end{array}$ \\
\hline logarea & Logarithm of floor area of the property, measured in square feet. \\
\hline ppi & $\begin{array}{l}\text { A quarterly property price index that tracks the movement of property prices in } \\
\text { Singapore. }\end{array}$ \\
\hline forcedsale & $\begin{array}{l}\text { Binary dummy variable indicating whether the property is a foreclosed property. The } \\
\text { dummy variable is one if the property is foreclosed. }\end{array}$ \\
\hline aucattempts & Number of times that the particular property was put on auction before it was sold. \\
\hline biddersprev & $\begin{array}{l}\text { Binary dummy variable indicating whether there were bidders for the property in the } \\
\text { previous auction attempt. }\end{array}$ \\
\hline salemtd & $\begin{array}{l}\text { Binary dummy variable indicating whether the property was sold by auction or by } \\
\text { negotiated sale. The dummy variable is one if the property was sold by auction. }\end{array}$ \\
\hline tbla & Number of days since last unsuccessful auction attempt. \\
\hline $\begin{array}{l}\text { dum_up } \\
\text { dum_down } \\
\text { dum_flat }\end{array}$ & $\begin{array}{l}\text { Binary dummy variable indicating the three phases of the property market over the period } \\
1995-2008 \text {. }\end{array}$ \\
\hline
\end{tabular}


Figure 2: Geographical Map of the Five Planning Regions in Singapore

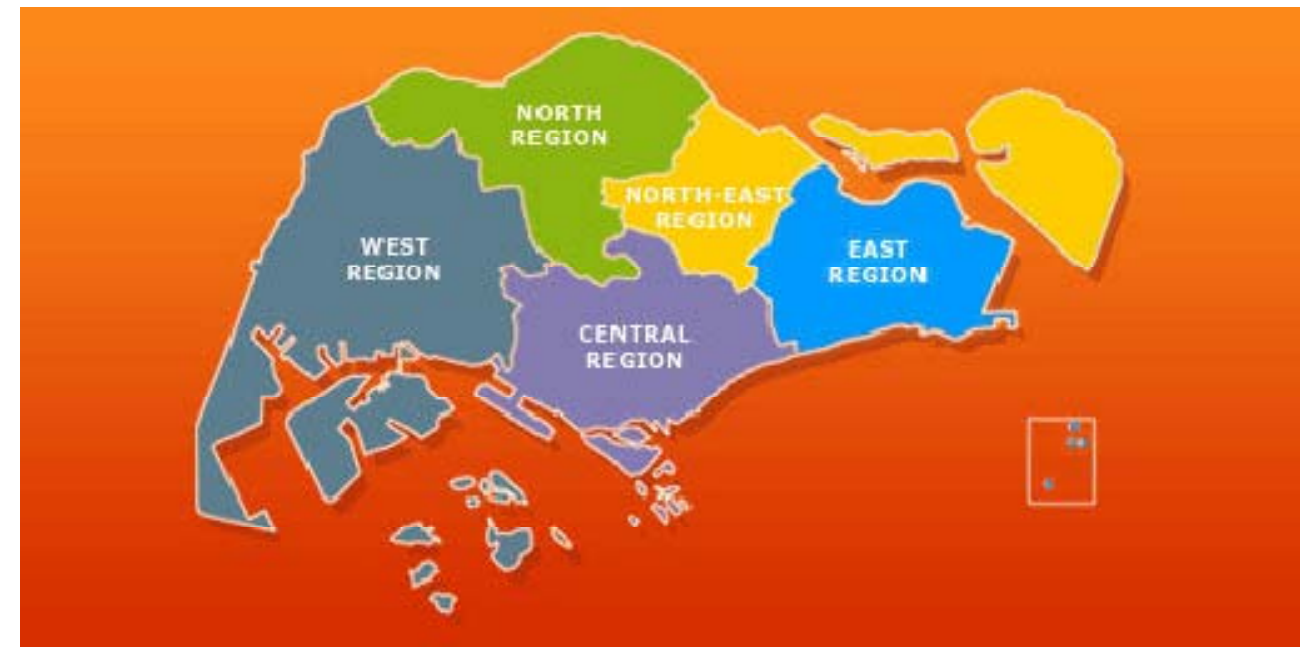

Source: URA website: http://www.ura.gov.sg/ppd/mp2003/index.jsp 
Figure 3: Property Price Index of Residential Properties

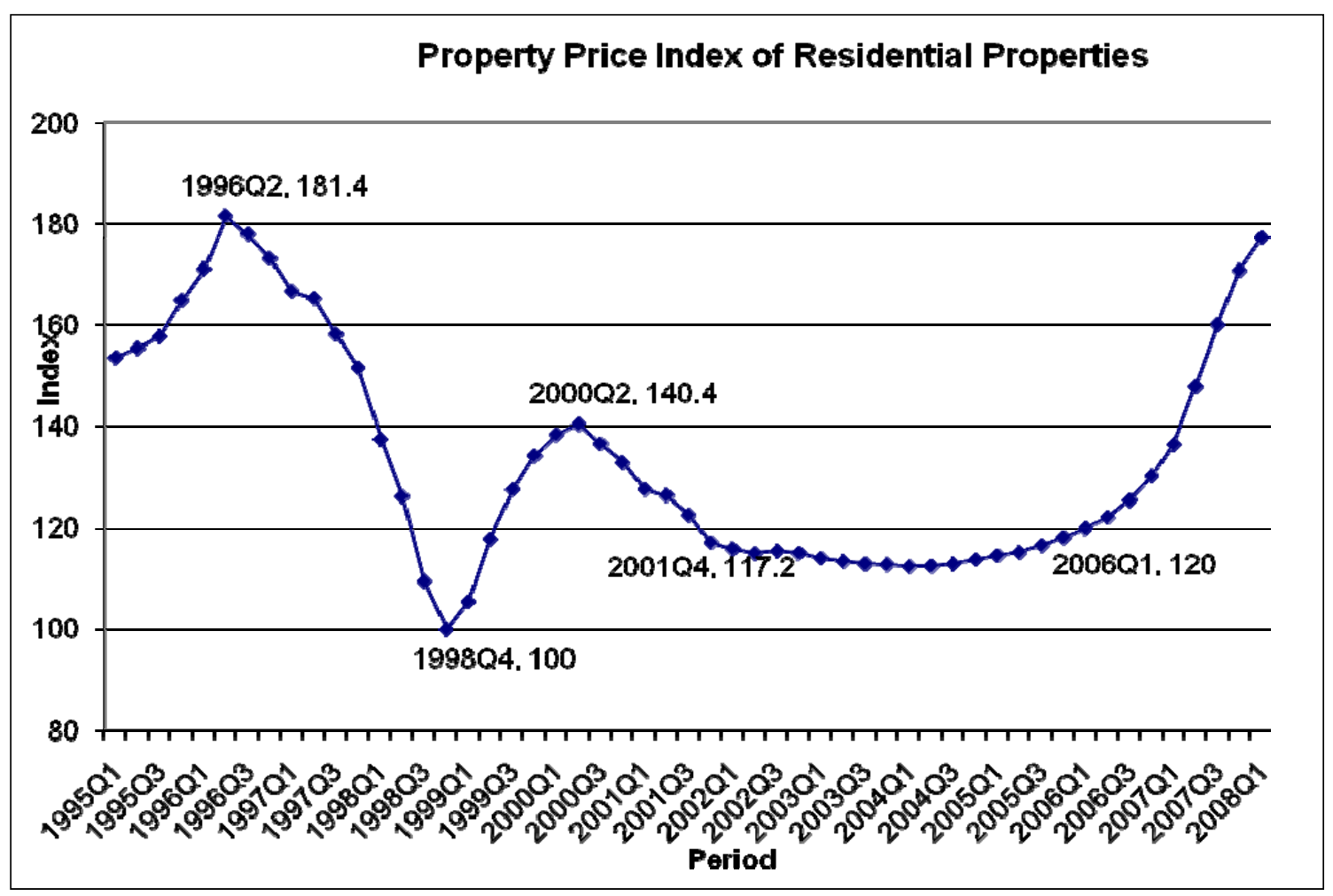

Source: Urban Redevelopment Authority 
Table 3: Descriptive Statistics

\begin{tabular}{|c|c|c|c|c|c|c|c|c|}
\hline & \multicolumn{2}{|c|}{$\begin{array}{c}\text { Full Sample } \\
(\mathrm{N}=3,022)\end{array}$} & \multicolumn{2}{|c|}{$\begin{array}{l}\text { NS Props } \\
(\mathrm{N}=2,245)\end{array}$} & \multicolumn{2}{|c|}{$\begin{array}{l}\text { Auction Props } \\
(\mathrm{N}=777)\end{array}$} & \multirow{2}{*}{\multicolumn{2}{|c|}{$\begin{array}{c}\text { Wilcoxon } \\
\text { Rank-Sum } \\
\text { Test }\end{array}$}} \\
\hline & Mean & Median & Mean & Median & Mean & Median & & \\
\hline price ('000) & 1,156 & 790 & 1,151 & 761 & 1,171 & 880 & -3.57 & $* *$ \\
\hline dum_apt & 0.59 & 1 & 0.60 & 1 & 0.57 & 1 & 1.12 & \\
\hline dum_ter & 0.14 & 0 & 0.13 & 0 & 0.16 & 0 & -2.24 & $* *$ \\
\hline dum_sd & 0.16 & 0 & 0.15 & 0 & 0.16 & 0 & -0.65 & \\
\hline dum_det & 0.11 & 0 & 0.12 & 0 & 0.10 & 0 & 1.47 & \\
\hline dum_pr1 & 0.52 & 1 & 0.50 & 0 & 0.58 & 1 & -3.71 & $* *$ \\
\hline dum_pr2 & 0.13 & 0 & 0.14 & 0 & 0.10 & 0 & 3.04 & $* *$ \\
\hline dum_pr3 & 0.17 & 0 & 0.16 & 0 & 0.17 & 0 & -0.25 & \\
\hline dum_pr4 & 0.06 & 0 & 0.06 & 0 & 0.06 & 0 & 0.08 & \\
\hline dum_pr5 & 0.13 & 0 & 0.14 & 0 & 0.10 & 0 & 2.70 & $* *$ \\
\hline tenuretype & 0.73 & 1 & 0.72 & 1 & 0.77 & 1 & -2.38 & $* *$ \\
\hline area & 3,058 & 1,776 & 3,142 & 1,733 & 2,818 & 1,864 & -1.66 & $*$ \\
\hline ppi & 119 & 115 & 120 & 115 & 118 & 116 & 0.94 & \\
\hline forcedsale & 0.71 & 1 & 0.68 & 1 & 0.80 & 1 & -6.46 & $* *$ \\
\hline aucattempts & 1.96 & 1 & 2.10 & 1 & 1.57 & 1 & 8.65 & $* *$ \\
\hline biddersprev & 0.08 & 0 & 0.09 & 0 & 0.05 & 0 & 3.46 & $* *$ \\
\hline tbla & 85 & 39 & 105 & 54 & 28 & 0 & 30.80 & $* *$ \\
\hline
\end{tabular}

Note:

** indicates a significance level of 5\%.

* indicates a significance level of $10 \%$. 
Table 4: Estimated Price Equations Conditional on Method-of Sale and Probit Model for Selection Equation

\begin{tabular}{|c|c|c|c|c|c|c|c|c|c|c|c|c|c|c|c|c|}
\hline \multirow{3}{*}{$\begin{array}{l}\text { Independent Variable } \\
\text { constant }\end{array}$} & \multicolumn{6}{|c|}{ Auction Sales } & \multicolumn{6}{|c|}{ Negotiated Sales } & \multicolumn{4}{|c|}{ Selection Eqn } \\
\hline & \multicolumn{2}{|c|}{ Model 1 (OLS) } & \multicolumn{2}{|c|}{$\begin{array}{c}\text { Model } 2 \\
\text { (Two-Step) }\end{array}$} & \multicolumn{2}{|c|}{ Model 3 (MLE) } & \multicolumn{2}{|c|}{ Model 1 (OLS) } & \multicolumn{2}{|c|}{$\begin{array}{c}\text { Model } 2 \\
\text { (Two-Step) }\end{array}$} & \multicolumn{2}{|c|}{ Model 3 (MLE) } & \multicolumn{2}{|c|}{ Probit Model } & \multicolumn{2}{|c|}{$\begin{array}{l}\text { Marginal } \\
\text { Effects }\end{array}$} \\
\hline & 3.1493 & $* *$ & 3.1554 & $* *$ & 3.1556 & $* *$ & 3.2305 & $* *$ & 3.2173 & $* *$ & 3.2223 & $* *$ & -0.7997 & & & \\
\hline & $(21.01)$ & & $(20.86)$ & & $(21.12)$ & & $(29.53)$ & & $(29.53)$ & & $(29.08)$ & & $-(1.41)$ & & & \\
\hline \multirow[t]{2}{*}{ dum_ter } & -0.0031 & & -0.0037 & & -0.0037 & & 0.0492 & $* *$ & 0.0486 & $* *$ & 0.0488 & $* *$ & 0.0129 & & 0.0038 & \\
\hline & $-(0.17)$ & & $-(0.20)$ & & $-(0.20)$ & & $(4.85)$ & & $(4.85)$ & & $(4.80)$ & & $(0.15)$ & & $(0.15)$ & \\
\hline \multirow[t]{2}{*}{ dum_sd } & -0.0120 & & -0.0115 & & -0.0115 & & 0.0453 & $* *$ & 0.0451 & $* *$ & 0.0452 & $* *$ & -0.0277 & & -0.0081 & \\
\hline & $-(0.53)$ & & $-(0.50)$ & & $-(0.51)$ & & $(2.84)$ & & $(2.82)$ & & $(2.83)$ & & $-(0.27)$ & & $-(0.27)$ & \\
\hline \multirow[t]{2}{*}{ dum_det } & -0.0059 & & -0.0052 & & -0.0052 & & 0.0960 & $* *$ & 0.0989 & $* *$ & 0.0979 & $* *$ & -0.2385 & & -0.0652 & $*$ \\
\hline & $-(0.18)$ & & $-(0.16)$ & & $-(0.16)$ & & $(4.12)$ & & $(4.27)$ & & $(4.26)$ & & $-(1.63)$ & & $-(1.78)$ & \\
\hline \multirow[t]{2}{*}{ tenuretype } & 0.1289 & $* *$ & 0.1286 & $* *$ & 0.1286 & $* *$ & 0.0728 & $* *$ & 0.0727 & $* *$ & 0.0728 & $* *$ & 0.0509 & & 0.0149 & \\
\hline & (8.60) & & (8.54) & & (8.61) & & $(9.84)$ & & (9.82) & & (9.83) & & $(0.77)$ & & $(0.77)$ & \\
\hline \multirow[t]{2}{*}{ dum_pr2 } & -0.0337 & & -0.0324 & & -0.0323 & & -0.0561 & $* *$ & -0.0525 & $* *$ & -0.0538 & $* *$ & -0.3222 & $* *$ & -0.0860 & $* *$ \\
\hline & $-(1.62)$ & & $-(1.53)$ & & $-(1.55)$ & & $-(7.48)$ & & $-(6.81)$ & & $-(7.14)$ & & $-(3.64)$ & & $-(4.08)$ & \\
\hline \multirow[t]{2}{*}{ dum_pr3 } & -0.0873 & $* *$ & -0.0867 & $* *$ & -0.0867 & $* *$ & -0.0926 & $* *$ & -0.0914 & $* *$ & -0.0918 & $* *$ & -0.0566 & & -0.0165 & \\
\hline & $-(6.94)$ & & $-(6.88)$ & & $-(6.94)$ & & $-(12.81)$ & & $-(12.63)$ & & $-(12.74)$ & & $-(0.73)$ & & $-(0.74)$ & \\
\hline \multirow[t]{2}{*}{ dum_pr4 } & -0.0750 & $* *$ & -0.0742 & $* *$ & -0.0742 & $* *$ & -0.0884 & $* *$ & -0.0874 & $* *$ & -0.0878 & $* *$ & -0.0738 & & -0.0212 & \\
\hline & $-(3.91)$ & & $-(3.82)$ & & $-(3.86)$ & & $-(9.77)$ & & $-(9.69)$ & & $-(9.70)$ & & $-(0.63)$ & & $-(0.64)$ & \\
\hline \multirow[t]{2}{*}{ dum_pr5 } & -0.0518 & $* *$ & -0.0506 & $* *$ & -0.0505 & $* *$ & -0.0375 & $* *$ & -0.0348 & $* *$ & -0.0358 & $* *$ & -0.2571 & $* *$ & -0.0701 & $* *$ \\
\hline & $-(2.65)$ & & $-(2.55)$ & & $-(2.58)$ & & $-(4.73)$ & & $-(4.34)$ & & $-(4.50)$ & & $-(2.99)$ & & $-(3.27)$ & \\
\hline \multirow[t]{2}{*}{ logarea } & 0.7684 & $* *$ & 0.7681 & $* *$ & 0.7681 & $* *$ & 0.7098 & $* *$ & 0.7076 & $* *$ & 0.7083 & $* *$ & 0.3036 & $*$ & 0.0896 & $*$ \\
\hline & (19.77) & & (19.62) & & (19.87) & & $(20.79)$ & & $(20.80)$ & & $(21.00)$ & & (1.95) & & (1.96) & \\
\hline \multirow[t]{2}{*}{ ppi } & 0.0014 & $* *$ & 0.0014 & $* *$ & 0.0014 & $* *$ & 0.0025 & $* *$ & 0.0026 & $* *$ & 0.0026 & $* *$ & -0.0058 & $* *$ & -0.0017 & $* *$ \\
\hline & $(2.44)$ & & (2.43) & & $(2.46)$ & & $(10.79)$ & & $(10.84)$ & & $(10.87)$ & & $-(2.44)$ & & $-(2.44)$ & \\
\hline \multirow[t]{2}{*}{ forcedsale } & -0.0189 & & -0.0204 & & -0.0205 & & -0.0264 & $* *$ & -0.0307 & $* *$ & -0.0291 & $* *$ & 0.3513 & $* *$ & 0.0975 & $* *$ \\
\hline & $-(1.43)$ & & $-(1.56)$ & & $-(1.58)$ & & $-(3.95)$ & & $-(4.12)$ & & $-(4.11)$ & & $(5.61)$ & & $(6.02)$ & \\
\hline \multirow[t]{2}{*}{ dum_up } & 0.0737 & $* *$ & 0.0715 & $* *$ & 0.0714 & $* *$ & 0.0171 & $* *$ & 0.0144 & $* *$ & 0.0154 & $* *$ & 0.3360 & $* *$ & 0.1025 & $* *$ \\
\hline & $(5.92)$ & & $(5.19)$ & & $(5.28)$ & & $(2.40)$ & & $(1.96)$ & & $(2.12)$ & & $(5.36)$ & & $(5.19)$ & \\
\hline \multirow[t]{2}{*}{ dum_down } & 0.0094 & & 0.0079 & & 0.0078 & & 0.0357 & $* *$ & 0.0321 & $* *$ & 0.0334 & $* *$ & 0.2935 & $* *$ & 0.0942 & $* *$ \\
\hline & $(0.59)$ & & $(0.49)$ & & $(0.49)$ & & $(3.49)$ & & $(3.03)$ & & (3.19) & & $(3.05)$ & & $(2.84)$ & \\
\hline
\end{tabular}




\begin{tabular}{|c|c|c|c|c|c|c|c|c|c|c|}
\hline biddersprev & & & & & & & $\begin{array}{r}-0.4273 \\
-(4.19)\end{array}$ & $* *$ & $\begin{array}{r}-0.1078 \\
-(5.03)\end{array}$ & $* *$ \\
\hline aucattempts & & & & & & & $\begin{array}{r}-0.1022 \\
-(5.71)\end{array}$ & ** & $\begin{array}{r}-0.0301 \\
-(5.73)\end{array}$ & ** \\
\hline TBLA & & & & & & & $\begin{array}{l}-0.0044 \\
-(14.50)\end{array}$ & $* *$ & $\begin{array}{l}-0.0013 \\
-(15.28)\end{array}$ & ** \\
\hline Inv Mills Ratio & & $\begin{array}{r}-0.0068 \\
-(0.49)\end{array}$ & $\begin{array}{r}-0.0071 \\
(0.30)\end{array}$ & & $\begin{array}{r}0.0275 \\
(1.47)\end{array}$ & $\begin{array}{r}0.0175 \\
(1.87)\end{array}$ & & & & \\
\hline No. of Obs & 777 & 777 & 777 & 2245 & 2245 & 2245 & 3022 & & & \\
\hline F-Stat & 163.45 & 152.74 & & 595.06 & 556.09 & & & & & \\
\hline $\mathrm{R} \mathrm{Sq}$ & 0.7239 & 0.7240 & & 0.8023 & 0.8025 & & & & & \\
\hline Root MSE & 0.1502 & 0.1503 & & 0.1345 & 0.1345 & & & & & \\
\hline Wald ChiSq & & & 2097.51 & & & 7790.55 & & & & \\
\hline Log Pseudolikelihood & & & -1120.518 & & & -172.038 & & & & \\
\hline LR Chisq & & & & & & & 448.51 & & & \\
\hline Pseudo Rsq & & & & & & & 0.1302 & & & \\
\hline Log Likelihood & & & & & & & -1498.3391 & & & \\
\hline
\end{tabular}

Note: The estimated price equations are shown in the first six columns. The dependent variable is the logarithm of the transacted price. The price equations are estimated using STATA with three different methods: (Model 1) Ordinary Least Squares, (Model 2) Heckman Two-Step Consistent Estimator, and (Model 3) Heckman Maximum Likelihood Estimator. The Probit Model is shown in the last two columns. The dependent variable is a binary dummy variable indicating whether the property was sold through auction ( $\mathrm{D}=1$ ) or negotiated sales $(\mathrm{D}=0) . * *$ indicates a significance level of $5 \%$ and $*$ indicates a significance level of $10 \%$. The $\mathrm{t}$-stats are reported in parentheses below the coefficients. The Wald test for the significance of the inverse Mills ratio using MLE is reported in parentheses below the lambda coefficient. 
Table 5: Comparison of Predictive versus Actual Values in the Probit Model

\begin{tabular}{llll} 
& & \multicolumn{2}{c}{ Estimated Values } \\
\cline { 3 - 4 } & & $\underline{0}$ & $\underline{1}$ \\
Actual Values & $\underline{0}$ & $73.3 \%$ & $1.0 \%$ \\
& $\underline{1}$ & $20.2 \%$ & $5.6 \%$
\end{tabular}


Table 6: Average Percentage Differentials based on Property Type, Market Conditions, and Location

\begin{tabular}{|l|c|c|c|c|}
\cline { 2 - 5 } \multicolumn{1}{c|}{} & All & Flat & Up & Down \\
\hline Both Samples & 8.17 & 6.63 & 11.65 & $3.68^{*}$ \\
Foreclosed & 8.55 & 6.97 & 12.38 & 5.01 \\
Non-Foreclosed & 7.23 & 5.42 & 10.42 & 1.91 \\
\hline Apartment & 8.91 & 7.14 & 12.71 & 5.59 \\
Terrace & 6.86 & 5.44 & 9.95 & 2.36 \\
Semi-Det & 8.36 & 7.02 & 12.17 & 3.53 \\
Detached & 5.65 & 4.32 & 8.51 & 0.83 \\
& & & & \\
\hdashline Region 1 & 8.54 & 6.97 & 12.12 & $3.81^{*}$ \\
Region 2 & 8.95 & 7.48 & 12.63 & $5.21^{*}$ \\
Region 3 & 7.66 & 6.12 & 11.45 & 2.24 \\
Region 4 & 8.63 & 7.68 & 11.02 & $5.12^{*}$ \\
Region 5 & 6.36 & 4.66 & 9.45 & $3.54^{*}$ \\
& & & & \\
\hline Max-Min & & & & \\
Property Types & 3.26 & 2.82 & 4.20 & 4.76 \\
Foreclosed & 3.61 & 3.22 & 3.81 & 4.48 \\
Non-Foreclosed & 2.39 & 2.07 & 4.03 & 4.30 \\
\hline
\end{tabular}

Note

* indicates that the statistic is insignificant at the $5 \%$ level. 
Table 7: Regression Estimation Explaining for Price Spread between Auction and Negotiated Sales

\begin{tabular}{|c|c|c|c|c|c|c|c|c|}
\hline $\begin{array}{l}\text { Independent } \\
\text { Variable }\end{array}$ & \multicolumn{2}{|l|}{ Full Sample } & \multicolumn{2}{|l|}{ Quantile 1} & \multicolumn{2}{|l|}{ Quantile 2} & \multicolumn{2}{|c|}{ Quantile 3} \\
\hline constant & $\begin{array}{c}0.0639 \\
(37.15)\end{array}$ & ** & $\begin{array}{c}0.0639 \\
(22.27)\end{array}$ & $* *$ & $\begin{array}{r}0.0650 \\
(25.34)\end{array}$ & $* *$ & $\begin{array}{c}0.0738 \\
(28.78)\end{array}$ & $* *$ \\
\hline price variance & $\begin{array}{r}-0.0115 \\
-(8.98)\end{array}$ & $* *$ & $\begin{array}{l}-0.0215 \\
-(12.77)\end{array}$ & $* *$ & $\begin{array}{r}-0.0150 \\
-(8.12)\end{array}$ & $* *$ & $\begin{array}{r}-0.0032 \\
-(1.71)\end{array}$ & $*$ \\
\hline dum_up & $\begin{array}{l}0.0571 \\
(36.24)\end{array}$ & $* *$ & $\begin{array}{c}0.0519 \\
(18.26)\end{array}$ & $* *$ & $\begin{array}{r}0.0577 \\
(24.14)\end{array}$ & $* *$ & $\begin{array}{l}0.0432 \\
(16.59)\end{array}$ & $* *$ \\
\hline dum_down & $\begin{array}{r}-0.0193 \\
-(8.92)\end{array}$ & $* *$ & $\begin{array}{r}-0.0043 \\
-(1.49)\end{array}$ & & $\begin{array}{r}-0.0194 \\
-(7.34)\end{array}$ & $* *$ & $\begin{array}{r}-0.0460 \\
-(9.15)\end{array}$ & $* *$ \\
\hline forcedsale & $\begin{array}{r}0.0183 \\
(12.74)\end{array}$ & $* *$ & $\begin{array}{r}0.0148 \\
(6.31)\end{array}$ & $* *$ & $\begin{array}{r}0.0217 \\
(10.11)\end{array}$ & $* *$ & $\begin{array}{r}0.0237 \\
(9.97)\end{array}$ & $* *$ \\
\hline No. of Obs & 3022 & & 906 & & 1208 & & 908 & \\
\hline F-Stat & 454.58 & & 158.52 & & 223.94 & & 163.38 & \\
\hline $\mathrm{R} \mathrm{Sq}$ & 0.426 & & 0.450 & & 0.4558 & & 0.4879 & \\
\hline Root MSE & 0.035 & & 0.030 & & 0.032 & & 0.033 & \\
\hline
\end{tabular}

Note:

The dependent variable is the estimated percentage price differential for property $i$, comparing the estimated auction sales price against the negotiated sales price. ** indicates a significance level of $5 \%$ and $*$ indicates a significance level of $10 \%$. 